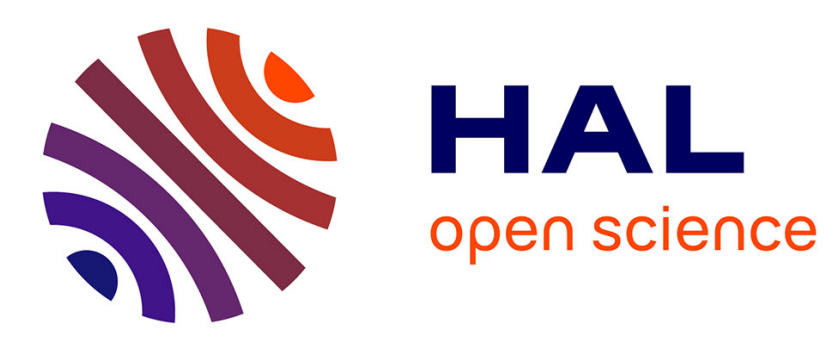

\title{
Physics-based computer simulation of the long-term effects of cardiac regenerative therapies
}

Lik Chuan Lee, Joakim Sundnes, Martin Genet, Samuel T. Wall

\section{To cite this version:}

Lik Chuan Lee, Joakim Sundnes, Martin Genet, Samuel T. Wall. Physics-based computer simulation of the long-term effects of cardiac regenerative therapies. Aerospace Technology, 2016, 04 (01), pp.23 - 29. 10.1142/S2339547816400069 . hal-01427485

\section{HAL Id: hal-01427485 https://hal.science/hal-01427485}

Submitted on 5 Jan 2017

HAL is a multi-disciplinary open access archive for the deposit and dissemination of scientific research documents, whether they are published or not. The documents may come from teaching and research institutions in France or abroad, or from public or private research centers.
L'archive ouverte pluridisciplinaire HAL, est destinée au dépôt et à la diffusion de documents scientifiques de niveau recherche, publiés ou non, émanant des établissements d'enseignement et de recherche français ou étrangers, des laboratoires publics ou privés. 


\title{
Physics-based Computer Simulation of the Long Term effects of Cardiac Regenerative Therapies
}

\author{
Lee, L.C. $\quad$ Sundnes, J.S. Genet, M. Wall, S.T.
}

June 10, 2015

\begin{abstract}
We describe the application of a computational model of left ventricular (LV) electromechanics, growth and remodeling to simulate the long term effects of cardiac regenerative therapies. The model is based on coupling a biophysically detailed model of short term cardiac electrophysiology and mechanics, to a model framework capable of predicting growth and remodeling over a longer time scale. The simulation considers two distinct concurrent and clinically relevant phases, namely, remodeling induced by a myocardial infarction, and the long term response following regenerative therapy to treat the infarct. Model predictions show post-infarct LV enlargement (hypertrophy) that is driven by abnormal strain values surrounding the infarct. Regenerative therapy tends to normalize the myofiber strain values and results in a reduction of LV size. These findings are consistent with experiments and clinical studies.
\end{abstract}

\section{Introduction}

Heart failure (HF) continues to pose a significant burden on our society. Between 2010 to 2030, the real cost of $\mathrm{HF}$ is projected to increase by a staggering $200 \%{ }^{12}$. Among all $\mathrm{HF}$ conditions, $70 \%$ of them are of systolic origin, with coronary artery diseases (CAD) accounting for approximately two thirds of these cases ${ }^{40}$. In the event of myocardial infarction in adult mammals, cardiomyocytes, unlike other cells, do not regenerate sufficiently to replace the lost ones and the end result is a permanent loss of contractile function in the infarcted region.

Current standard therapy for treating myocardial infarction (MI) includes pharmacological treatments such as the admininstration of thrombolytic agents to restore coronary blood flow and angiotensin converting enzyme inhibitors to reduce blood pressure ${ }^{2}$. The long-term prognosis of MI remained poor. Although current treatments have improved MI survival dramatically, around $24 \%$ of MI survivors progress to develop $\mathrm{HF}^{41}$ that has limited treatment options. To address this issue, a myriad of new devices and treatments for MI have been developed in recent years including, for instance, surgical ventricular restoration ${ }^{4}$, ventricular partitioning device ${ }^{30}$, and cardiac regenerative therapies ${ }^{6,48}$.

Among these treatments, cell-based cardiac regenerative therapies have garnered a considerable interest lately and multiple strategies to regenerate diseased hearts are currently 
under investigation. These strategies include the direct transplantation of stem cells into the infarcted myocardium, and the reprogramming of residing non-myocytes to cardiomyocytes in the diseased heart ${ }^{6}$. A number of clinical and experimental studies on these regenerative therapies have shown favorable post-treatment outcome in the form of attenuation or reversal of adverse myocardial remodeling ${ }^{31,45}$. The same positive outcome was, however, not found in other studies ${ }^{28}$. A better understanding of the effects of cardiac regenerative therapies is, therefore, very much needed before they can be applied optimally to treat MI.

Computational modeling has been used to develop an understanding of heart disease treatments ${ }^{20,25,26,42,44}$ and offers a useful and efficient way to understand the effects and mechanisms of treatments ${ }^{22}$. While most computational models of the heart are limited to simulating the immediate acute effects resulting from a treatment, recent advancement in theory and model development have led to an emerging class of computational models that can describe the long term cardiac remodeling process ${ }^{10,17,21}$. Although this branch of modeling is an emerging field and all models are fairly recent, a number of these models have been used to evaluate the long term effects of HF and treatments ${ }^{16,18}$.

Here, we utilized a recently developed electromechanics-growth model ${ }^{23}$ to simulate the long-term effects of cardiac regenerative therapies. This growth model was established previously based on the principle that myocytes undergo hypertrophy or atrophy in order to restore strain homeostasis ${ }^{21}$. Simulations using this model has shown that the collective behavior of myocytes in response to global mechanical loading and unloading results in, respectively, the dilation and shrinkage of the left ventricle (LV). This feature was found in hearts that have been implanted with a left ventricular assist device ${ }^{5}$. By applying this model to simulate the effects of cardiac regenerative therapies, we seek to test whether the model prediction is consistent with those found in experiments and clinical studies. Doing so will also enable us to understand how the surviving cardiomyocytes in the non-infarcted region respond collectively to the regional restoration of tissue contractile function at the infarct where new myocytes are introduced. Upon calibration with experimental studies and clinical data, this model will enable us to gain a deeper insight into the mechanism of cardiac regenerative therapies.

The paper is organized as follows. In Section 2, we briefly outline the electromechanicsgrowth model and describe details of the simulation setup. Section 3 presents the simulation results while the findings and limitations are discussed in Section 4. Finally, we summarize our findings and present preliminary conclusions in Section 5.

\section{Methods}

\subsection{Electromechanical-growth model}

The electromechanics-growth model is described in details in Lee et al. ${ }^{23}$. Briefly, the model is an integration of a cardiac growth constitutive model ${ }^{21}$ with a cardiac electromechanics model $^{38}$. Long term cardiac growth was described in the model using the theoretical framework in which the deformation gradient tensor $\boldsymbol{F}$ was multiplicatively decomposed into a growth tensor $\boldsymbol{F}_{g}$ and an elastic deformation tensor $\boldsymbol{F}_{e}$, i.e., $\boldsymbol{F}=\boldsymbol{F}_{e} \cdot \boldsymbol{F}_{g}{ }^{34}$. A constitutive relationship was prescribed for $\boldsymbol{F}_{g}$, so that growth and reverse growth occurs only along the cardiomyocyte long axis, and only if the myocyte stretch is outside of a prescribed interval 
of homeostatic stretch values. No growth occurs if the myocyte stretch stays within the prescribed homeostatic interval. This constitutive relation was formulated based on previous experimental studies showing that (1) volume overload in ischemic cardiomyopathy causes cardiomyocytes to become elongated ${ }^{9}$ and (2) this behavior can be reversed upon removal of the overloading conditions ${ }^{8,14}$.

On a shorter timescale, cardiac electrophysiology (EP) was described using the standard bidomain equations and a cellular EP model ${ }^{47}$; and cardiac mechanics was described with a passive material model ${ }^{11}$ and an active contraction model ${ }^{33}$. The electromechanical behavior of the heart is described by coupling these models ${ }^{38}$.

Because the cardiac growth model ${ }^{21}$ and the electromechanics model ${ }^{38}$ operate at two different timescales, i.e., growth and remodeling becomes appreciable only after a large number of heart beats, a separation of timescale was invoked to integrate the two models. Two assumptions are essential for the separation of time scales. The first assumption is that growth and remodeling occurs too slowly to be detectable on the time scale of a single heart beat. Correspondingly, the growth tensor $\boldsymbol{F}_{g}$ remains constant within a cardiac cycle in our simulation. The second assumption is that the stimuli that drive growth and remodeling can be derived from a representative cardiac cycle. The simulation of a cardiac cycle then becomes equivalent to that of a "growth cycle" within which growth and remodeling is not detectable and does not affect the electromechanics of the heart. By invoking these assumptions, the growth tensor is updated once for every cardiac cycle, which enables us to prescribe the time-average stretch over a cardiac cycle as the stimulant for cardiomyocytes growth ${ }^{13}$.

\subsection{Left ventricular geometry}

The electromechanics-growth model was applied to a human left ventricular geometry that was reconstructed from magnetic resonance images ${ }^{7}$. Three distinct regions were prescribed in the LV, namely, (i) the infarct, (ii) the borderzone and (iii) the remote (healthy) regions.

LV geometry



\section{Myofiber orientation}

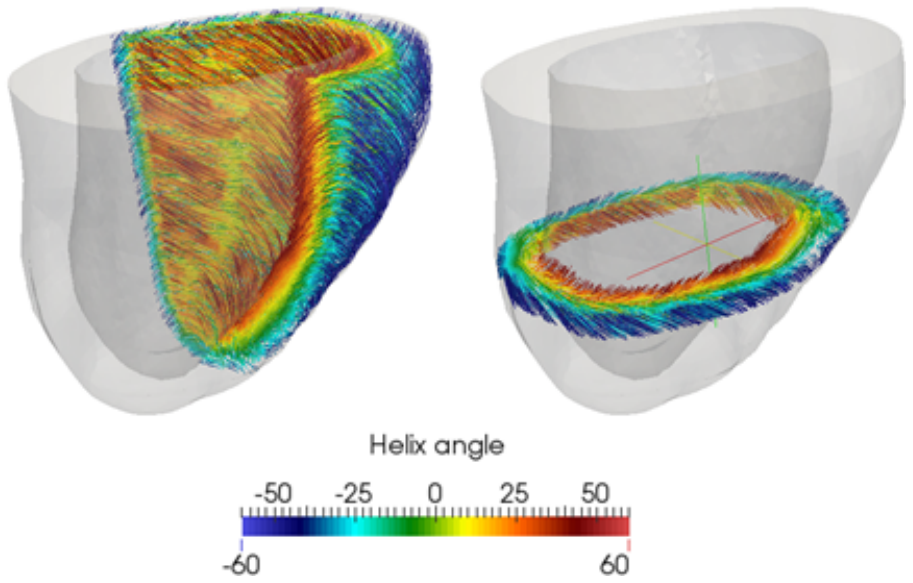

Figure 1: Schematic of the left ventricular infarct model and myofiber orientation color coded with the prescribed myofiber helix angle. 
These regions differ from each other only in terms of the prescribed tissue contractility, a material parameter that is denoted by the "reference tension" in the active contraction model $^{33}$. The infarct was assumed to be devoid of cardiomyocytes and was prescribed to be non-contractile. On the other hand, the borderzone region was prescribed to have one-half the contractility of the remote region as direct active force measurements on cardiomyocytes taken from the borderzone were found to have depressed contractility ${ }^{36}$. The helix angle that defines the cardiomyocytes long-axis was prescribed to vary linearly across the myocardial wall from $-60^{\circ}$ (endocardium) to $60^{\circ}$ (epicardium) in the entire LV based on previous histological studies ${ }^{37}$ (Figure 1). The LV model was coupled to a 3-parameter Windkessel model to simulate the ejection phase in a cardiac cycle. The regional homeostatic cardiomyocytes stretch was obtained from the solution for the time-average stretch over a cardiac cycle $\bar{\lambda}_{e}$ in the same LV model with normal contractile function where the infarct and borderzone have contractilities equal to that in the remote region. Standard finite element method was used to solve the LV computational model. More details and all the parameters associated with the model can be found in Lee et al. ${ }^{23}$.

\subsection{Simulation protocol}

To simulate the effects of cardiac regenerative therapies via the introduction of new contractile cardiomyocytes into the myocardium, the following two-phase simulation protocol was implemented. First, in the remodeling phase, the model was run for 5 growth cycles with impaired contractility in the infarct and borderzone. Then, the post-treatment phase was simulated by restoring infarct and borderzone contractility back to their normal values and running the model for another 10 growth cycles. Because the focus here is on growth and reverse growth due to cellular hypertrophy and atrophy of the residing cardiomyocytes, respectively, the infarct, which was assumed to be devoid of cardiomyocytes, is prohibited from growing.

\section{Results}

\subsection{Pressure-volume relationship}

Our simulation results show a right shift of the pressure-volume (PV) loop during the first 5 cycles when a non-contractile infarct and a borderzone with depressed contractility are present in the LV. Compared to the LV with normal contractile function which has an ejection fraction (EF) of $49 \%$, the infarcted LV shows a substantially smaller PV loop in the first cycle $(\mathrm{EF}=32 \%)$ that shifts towards the right in the next 4 cycles (EF at cycle $5=$ $26 \%)$.

Restoration of the infarct and borderzone contractilities back to the normal values in the post-treatment simulation phase led to an expected larger PV loop, with EF $=47 \%$. In subsequent cycles, the PV loop shifts towards the left (Figure 2b) and the EF was maintained in these cycles. 


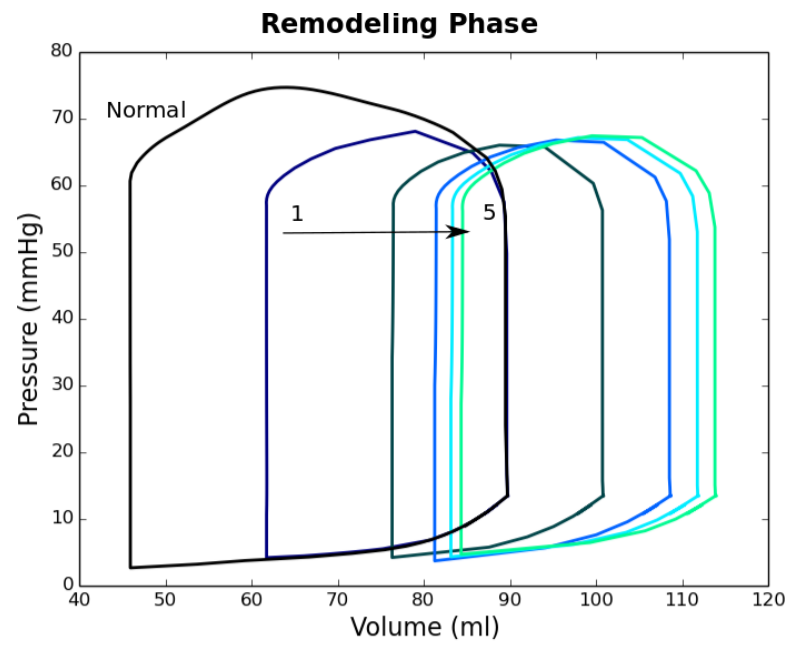

(a)

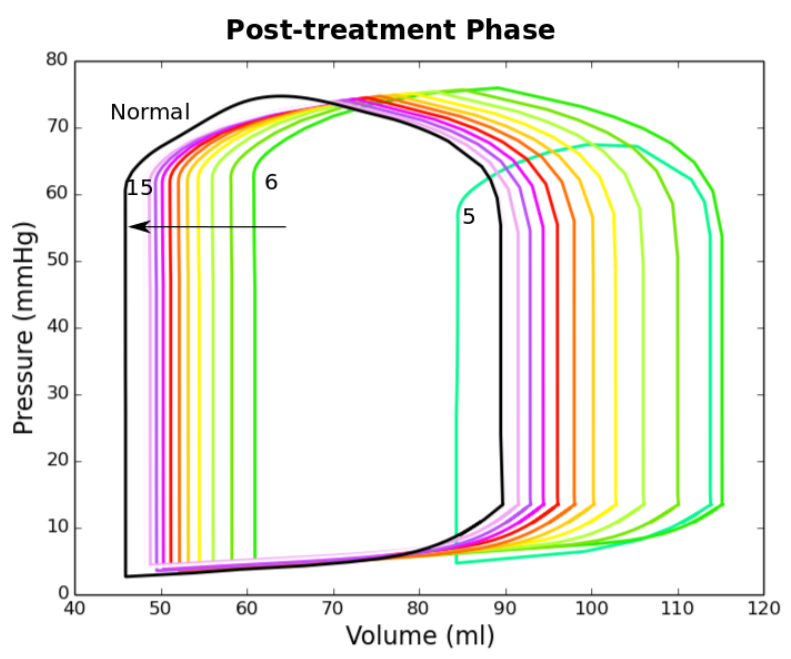

(b)

Figure 2: Pressure-volume loop (a) remodeling phase and (b) post-treatment phase.

\subsection{Geometrical changes}

The shifting of PV loops is reflected by a change in the LV geometry. During the remodeling phase, the LV became more dilated and spherical (Figure 3a). The growth magnitude was measured by the determinant of the growth tensor i.e, $\operatorname{det} \boldsymbol{F}_{g}$. Growth of the LV occurs primarily at the borderzone as indicated by the larger values of $\operatorname{det} \boldsymbol{F}_{g}$ in that region. This growth results from a lengthening of the cardiomyocytes in the infarct borderzone.

During the post-treatment phase, the growth process was reversed and the LV became

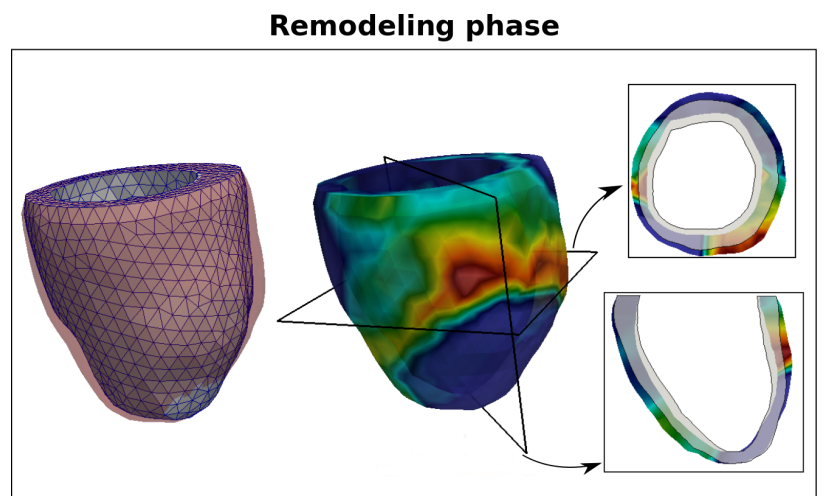

(a)

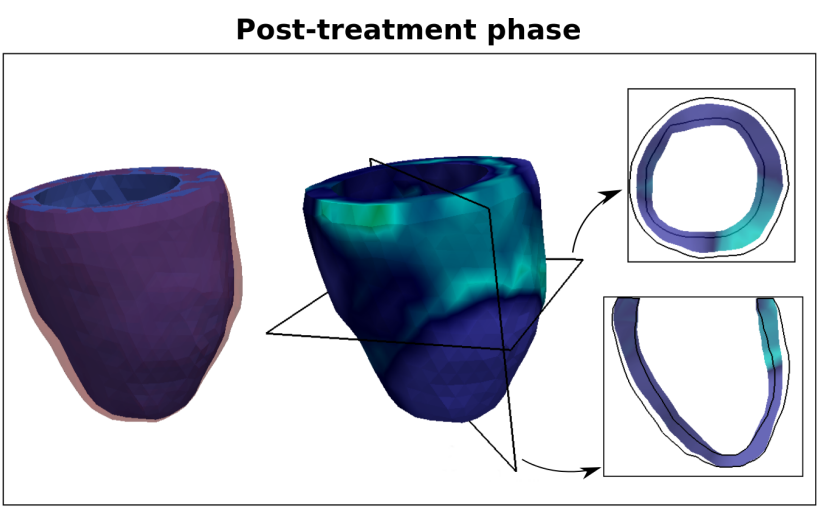

(b)

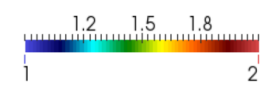

Figure 3: Geometrical changes of the LV during (a) remodeling and (b) post-treatment phases. Leftmost: LV end-diastolic configuration at (a) cycle 5 (red) superimposed to that at cycle 1 (grey) and (b) cycle 15 (blue) superimposed to that in cycle 6 (red). Middle: Determinant of growth tensor $\operatorname{det} \boldsymbol{F}_{g}$ at (a) cycle 5 and (b) cycle 15. Rightmost: corresponding long and short-axis view. Black lines in these views denote the same cross section at the beginning of the two simulation phases. Note: $\operatorname{det} \boldsymbol{F}_{g}$ is prescribed to remain constant at 1 in the infarct. 
progressively smaller and more ellipsoidal (Figure 3b). Correspondingly, the growth magnitude $\operatorname{det} \boldsymbol{F}_{g}$ decreases at the borderzone, reflecting the shortening of cardiomyocytes in its longitudinal axis.

\subsection{Myofiber stretch}

At the beginning of the remodeling phase (cycle 1), the time-averaged elastic myofiber stretch $\bar{\lambda}_{e}$ is higher at the infarct and borderzone compared to that found in the normal LV (Figure 4). In subsequent cycles during this phase, $\bar{\lambda}_{e}$ decreases in the borderzone and approaches that found in the normal LV. With growth (cycle $1-5$ ), however, $\bar{\lambda}_{e}$ decreases in the borderzone and approaches that in the normal LV. At the infarct, which was prescribed not to grow, the time-averaged elastic myofiber stretch did not decrease but increased slightly during the remodeling phase. We note that the reason why $\bar{\lambda}_{e}$ is highest at the infarct is because the infarct did not contract and underwent stretching even during systole.

In the post-treatment phase, contractility was restored at the infarct and borderzone and the immediate effect (in cycle 6) was a reduction of $\bar{\lambda}_{e}$ in these regions. The reduced values are below the corresponding homeostatic values found in the normal LV. In subsequent cycles of the post-treatment phase, the time-averaged elastic myofiber stretch in the borderzone and infarct increased and approached their respective homeostatic values.
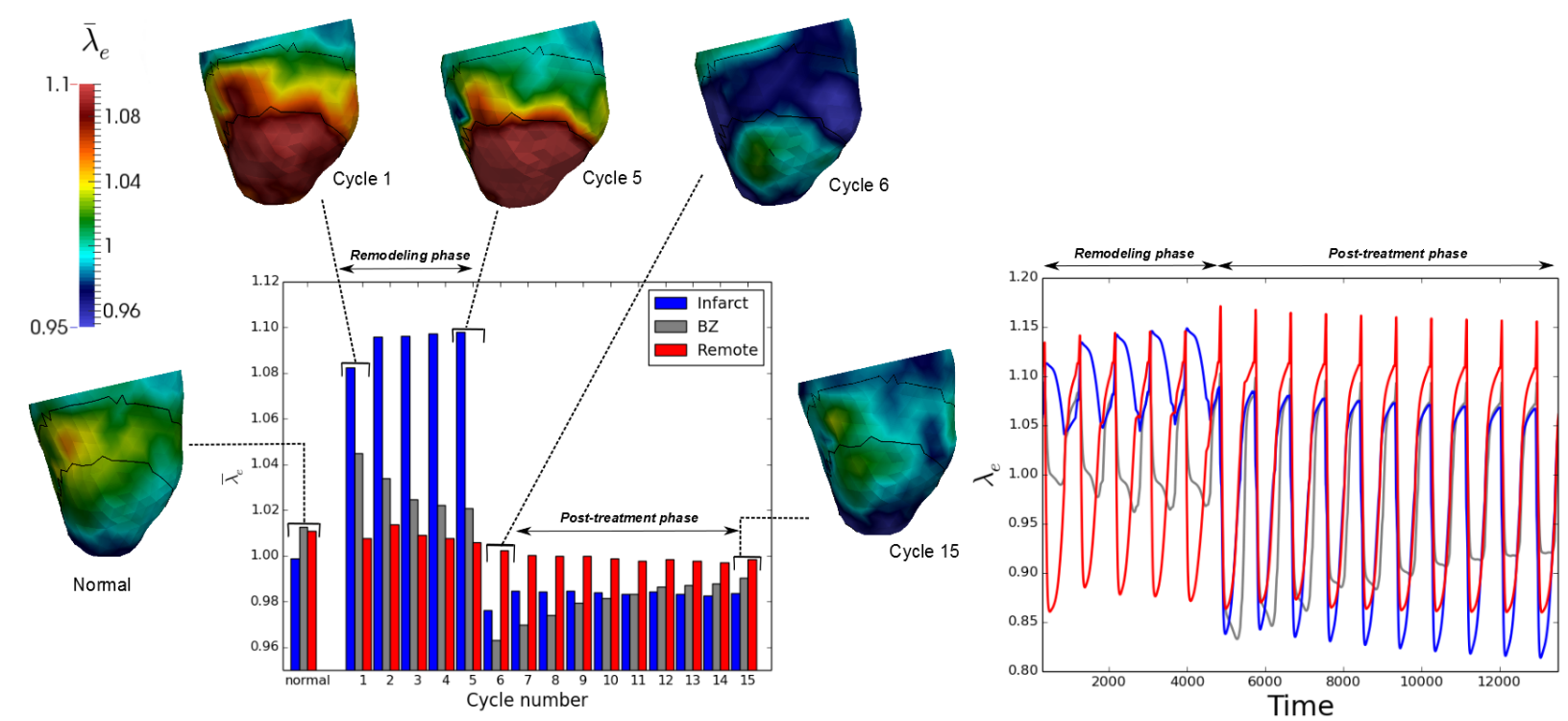

Figure 4: Left: time-average myofiber stretch $\bar{\lambda}_{e}$ at the infarct, borderzone and remote regions in the two simulation phase. Right: myofiber stretch taken at arbitary points from each of these regions. (Same color scheme applied here). Note that: infarct and borderzone were regenerated at the end of cycle 5 .

\section{Discussion}

Although computational models have been used to simulate the long term effects of heart diseases and therapies ${ }^{10,18,32}$, most of these models are only capable of simulating growth 
based on standard time points in the cardiac cycle (e.g., end-of-diastole or end-of-systole). As such, time-averaged, minima or maxima of local deformation signals, which were found to be likely candidates for driving hypertrophy ${ }^{13}$, cannot be applied in these models as growth stimulant. Here, we have used the time-averaged myofiber stretch as the growth stimulant and have, for the first time, applied the electromechanics-growth model to simulate the effects of cardiac regenerative therapies. Our simulation results show features that are generally consistent with experimental and clinical studies, both in the remodeling and reverse remodeling phase.

\subsection{Remodeling phase}

During the remodeling phase, our model predicts that the time-average myofiber stretch becomes higher in the borderzone and infarct than that found in the normal LV (Figure 4). Therefore, growth occurs mostly in the borderzone and the LV becomes dilated and more spherical as a result (Figure 3). Globally, the LV dilation is manifested by a shifting of the PV loop towards the right (Figure 2).

All these features are consistent with experimental and clinical studies both at the cellular and organ level. First, abnormal stretch in the form of a reduced contractile deformation during systole is a widely observed feature in the borderzone after $\mathrm{MI}^{3,19}$. Correspondingly, cardiomyocytes in the borderzone region would, when averaged over a cardiac cycle, undergo higher stretching. Second, cardiomyocytes in the borderzone of animal MI models have displayed appreciable hypertrophy when compared to those at remote region ${ }^{15,36}$. For example, cardiomyocytes cross sectional area was found to be about $70 \%$ higher than that in the remote region 2 weeks after MI in sheep hearts ${ }^{36}$ whereas isolated cardiomyocytes from explanted human hearts with ischemic dilated cardiomyopathy were measured to be about $40 \%$ longer than those found in normal heart ${ }^{9}$. Third, at the organ level, progressive LV dilation, in the form of a parallel increase in both end-diastolic volume and end-systolic volume that results in a right shift of the PV loop is a pathophysiological feature of MI that is found in both humans and animals ${ }^{29,39}$.

\subsection{Post-treatment phase}

Restoration of the infarct and borderzone contractility to their normal values in our simulation led to an immediate increase in both stroke volume and EF. The time-average myofiber stretch also decreases immediately and fell below their corresponding homeostatic values in the infarct and borderzone (Figure 4). As a result, cardiomyocytes in the borderzone growth was predicted by our simulation to undergo atrophy and growth was reversed during the post-treatment phase (Figure 3). This reversal is manifested globally by a decrease in the LV size that is associated with the shifting of PV loop towards the left (Figure 2).

Because the effects of cardiac regenerative therapies are still not widely established, and at times, controversial ${ }^{35}$, it is difficult to assess, with certainty, that our model predictions agree with the features found in experiments and clinical studies of this class of therapies. Nevertheless, it is worthwhile to discuss our model prediction in the context of some these studies. In general, cardiac regenerative therapies have been found to be effective in improving long term cardiac function ${ }^{31,46}$, although other studies have found the contrary to 
be true ${ }^{27}$. Studies that found positive effects in this treatment have shown that the introduction of new contractile cardiomyocytes can attenuate ${ }^{31}$ or even reverse ${ }^{46}$ the remodeling process associated with MI. Specifically, in vivo reprogramming of fibroblasts into contracting cardiomyocytes-like cells in a murine infarct model led to an increase in stroke volume and ejection fraction ${ }^{31}$. Similarly, intramyocardial injections of bone marrow progenitor cells into the infarct and borderzone of MI patients was found to lead to significant reverse remodeling where both EDV and ESV were decreased by $20 \%$ at 1 year follow up ${ }^{46}$. These findings are consistent with our model predictions.

Besides functional change at the global level, postmortem analysis in porcine hearts implanted with mesenchymal stem cell (MSC) have also found that the cardiomyocytes in the sub-endocardial rim of the MI are not hypertrophied when compared to those taken from the remote region ${ }^{1}$. It is unclear, however, as to whether these unhypertrophied cardiomyocytes are proliferated endogeneous cardiomyocytes or newly differentiated cardiomyocytes. Irrespective of this result, our model prediction suggesting that hypertrophy will regress in the cardiomyocytes at the infarct and borderzone upon restoration of the tissue contractility is consistent with this finding.

\subsection{Limitations}

There are several limitations associated with this study. First, we did not consider the effects of infarct expansion, which are events that occur early in the course of MI that lead infarct thinning ${ }^{43}$. Second, we did not take into account that the borderzone can extend itself during the remodeling ${ }^{15}$. Although the borderzone in our simulation expands in size via cellular hypertrophy, this effect is different from the extension of borderzone width via the recruitment of previously healthy myocardium into this dysfunctional zone. Last, we did not take into account the immediate increase in LV wall volume after injection of new cells or retroviral particles that some of these cardiac therapies were based on. Although the injected volume is small compared to the LV wall volume in some studies (e.g., $2.5 \mathrm{ml}$ injection vs. LV wall volume of $\sim 150 \mathrm{ml}^{46}$ ), there are other studies in which the injected volume is significant (e.g. $15 \mathrm{ml}$ injection vs. $\mathrm{LV}$ wall volume of $\sim 50 \mathrm{ml}^{1}$ ). As shown in a number of modeling studies, injection of new non-contractile materials into the LV wall can have an immediate impact on the regional mechanics that would affect the remodeling $\operatorname{process}^{24,42}$.

\section{Conclusion}

In summary, we have applied a recently developed computational model to simulate the long-term effects of cardiac regenerative therapies and have shown that the model is able to predict a number of features found in clinical and experimental studies. For the model to be quantitatively accurate, appropriate refinement and calibration with longitudinal studies involving animal models and patient data is necessary. Our future studies will focus on this aspect. 


\section{Acknowledgements}

This work was supported by the Marie Curie International Outgoing Fellowship within the 7th European Community Framework Program (M. Genet). 


\section{References}

[1] Amado, L. C., Schuleri, K. H., Saliaris, A. P., Boyle, A. J., Helm, R., Oskouei, B., Centola, M., Eneboe, V., Young, R., Lima, J. A. C., Lardo, A. C., Heldman, A. W. and Hare, J. M. Multimodality Noninvasive Imaging Demonstrates In Vivo Cardiac Regeneration After Mesenchymal Stem Cell Therapy J. Am. Coll. Cardiol. 48, 21162124 (2006).

[2] Antman, E. M. ACC/AHA Guidelines for the Management of Patients With STElevation Myocardial Infarction-Executive Summary: A Report of the American College of Cardiology/American Heart Association Task Force on Practice Guidelines (Writing Committee to Revise the 1999 Circulation 110, 588-636 (2004).

[3] Ashikaga, H., Mickelsen, S. R., Ennis, D. B., Rodriguez, I., Kellman, P., Wen, H. and McVeigh, E. R. Electromechanical analysis of infarct border zone in chronic myocardial infarction. Am. J. Physiol. Heart Circ. Physiol. 289, H1099-H1105 (2005).

[4] Athanasuleas, C. L., Buckberg, G. D., Stanley, A. W. H., Siler, W., Dor, V., Di Donato, M., Menicanti, L., Almeida de Oliveira, S., Beyersdorf, F., Kron, I. L., Suma, H., Kouchoukos, N. T., Moore, W., McCarthy, P. M., Oz, M. C., Fontan, F., Scott, M. L. and Accola, K. A. Surgical ventricular restoration in the treatment of congestive heart failure due to post-infarction ventricular dilation. J. Am. Coll. Cardiol. 44, 1439-45 (2004).

[5] Burkhoff, D., Klotz, S. and Mancini, D. M. LVAD-induced reverse remodeling: basic and clinical implications for myocardial recovery. J. Card. Fail. 12, 227-39 (2006).

[6] Garbern, J. C. and Lee, R. T. Cardiac stem cell therapy and the promise of heart regeneration. Cell Stem Cell 12, 689-98 (2013).

[7] Genet, M., Lee, L. C., Ge, L., Acevedo-Bolton, G., Jeung, N., Martin, A. J., Cambronnero, N., Boyle, A., Yeghiazarians, Y., Kozerke, S. and Guccione, J. M. A novel method for quantifying smooth regional variations in myocardial contractility within an infarcted human left ventricle based on delay-enhanced magnetic resonance imaging. $J$. Biomech. Eng. (In press).

[8] Gerdes, A. M., Clark, L. C. and Capasso, J. M. Regression of cardiac hypertrophy after closing an aortocaval fistula in rats. Am. J. Physiol. 268, H2345-51 (1995).

[9] Gerdes, A. M., Kellerman, S. E., Moore, J. A., Muffly, K. E., Clark, L. C., Reaves, P. Y., Malec, K. B., McKeown, P. P. and Schocken, D. D. Structural remodeling of cardiac myocytes in patients with ischemic cardiomyopathy Circulation 86, 426-430 (1992).

[10] Göktepe, S., Abilez, O. J., Parker, K. K. and Kuhl, E. A multiscale model for eccentric and concentric cardiac growth through sarcomerogenesis. J. Theor. Biol. 265, 433-42 (2010). 
[11] Guccione, J. M., McCulloch, A. D. and Waldman, L. K. Passive material properties of intact ventricular myocardium determined from a cylindrical model. J. Biomech. Eng. 113, 42-55 (1991).

[12] Heidenreich, P. A., Trogdon, J. G., Khavjou, O. A., Butler, J., Dracup, K., Ezekowitz, M. D., Finkelstein, E. A., Hong, Y., Johnston, S. C., Khera, A., Lloyd-Jones, D. M., Nelson, S. A., Nichol, G., Orenstein, D., Wilson, P. W. F. and Woo, Y. J. Forecasting the future of cardiovascular disease in the United States: A policy statement from the American Heart Association Circulation 123, 933-944 (2011).

[13] Holmes, J. W. Candidate mechanical stimuli for hypertrophy during volume overload. J. Appl. Physiol. 97, 1453-1460 (2004).

[14] Hutchinson, K. R., Guggilam, a., Cismowski, M. J., Galantowicz, M. L., West, T. a., Stewart, J. a., Zhang, X., Lord, K. C. and Lucchesi, P. A. Temporal pattern of left ventricular structural and functional remodeling following reversal of volume overload heart failure J. Appl. Physiol. 111, 1778-1788 (2011).

[15] Jackson, B. M., Gorman, J. H., Moainie, S. L., Guy, T. S., Narula, N., Narula, J., JohnSutton, M. G., Edmunds, L. H. and Gorman, R. C. Extension of borderzone myocardium in postinfarction dilated cardiomyopathy. J. Am. Coll. Cardiol. 40, 1160-7 (2002).

[16] Kerckhoffs, R. C. P., Omens, J. H. and McCulloch, A. D. Mechanical discoordination increases continuously after the onset of left bundle branch block despite constant electrical dyssynchrony in a computational model of cardiac electromechanics and growth. Europace 14, v65-v72 (2012a).

[17] Kerckhoffs, R. C. P., Omens, J. and McCulloch, A. D. A single strain-based growth law predicts concentric and eccentric cardiac growth during pressure and volume overload. Mech. Res. Commun. 42, 40-50 (2012b).

[18] Klepach, D., Lee, L. C., Wenk, J. F., Ratcliffe, M. B., Zohdi, T. I., Navia, J. A., Kassab, G. S., Kuhl, E. and Guccione, J. M. Growth and remodeling of the left ventricle: A case study of myocardial infarction and surgical ventricular restoration. Mech. Res. Commun. 42, 134-141 (2012).

[19] Kramer, C. M., Lima, J. A., Reichek, N., Ferrari, V. a., Llaneras, M. R., Palmon, L. C., Yeh, I. T., Tallant, B. and Axel, L. Regional differences in function within noninfarcted myocardium during left ventricular remodeling. Circulation 88, 1279-1288 (1993).

[20] Lee, L. C., Ge, L., Zhang, Z., Pease, M., Nikolic, S. D., Mishra, R., Ratcliffe, M. B. and Guccione, J. M. Patient-specific finite element modeling of the Cardiokinetix Parachute device: Effects on left ventricular wall stress and function Med. Biol. Eng. Comput. 52, 557-566 (2014).

[21] Lee, L. C., Genet, M., Acevedo-Bolton, G., Ordovas, K., Guccione, J. M. and Kuhl, E. A computational model that predicts reverse growth in response to mechanical unloading Biomech. Model. Mechanobiol. 14, 217-29 (2015). 
[22] Lee, L. C., Genet, M., Dang, A. B., Ge, L., Guccione, J. M. and Ratcliffe, M. B. Applications of computational modeling in cardiac surgery J. Card. Surg. 29, 293-302 (2014).

[23] Lee, L. C., Sundnes, J., Genet, M., Wenk, J. F. and Wall, S. T. An Integrated Electromechanical-Reversible Growth Heart Model for Simulating Cardiac Therapies Biomech. Model. Mechanobiol. (Submitted).

[24] Lee, L. C., Wall, S. T., Genet, M., Hinson, A. and Guccione, J. M. Bioinjection treatment: Effects of post-injection residual stress on left ventricular wall stress J. Biomech. 47, 3115-3119 (2014).

[25] Lee, L. C., Wall, S. T., Klepach, D., Ge, L., Zhang, Z., Lee, R. J., Hinson, A., Gorman, J. H., Gorman, R. C. and Guccione, J. M. Algisyl-LVR with coronary artery bypass grafting reduces left ventricular wall stress and improves function in the failing human heart. Int. J. Cardiol. pp. 1-7 (2013).

[26] Lee, L. C., Wenk, J. F., Zhong, L., Klepach, D., Zhang, Z., Ge, L., Ratcliffe, M. B., Zohdi, T. I., Hsu, E., Navia, J. L., Kassab, G. S. and Guccione, J. M. Analysis of Patientspecific Surgical Ventricular Restoration - Importance of an Ellipsoidal Left Ventricular Geometry for Diastolic and Systolic Function. J. Appl. Physiol. pp. 136-144 (2013).

[27] Lunde, K., Solheim, S., Aakhus, S., Arnesen, H., Abdelnoor, M., Egeland, T., Endresen, K., Ilebekk, A., Mangschau, A., Fjeld, J. G., Smith, H. J. r., Taraldsrud, E., Grø gaard, H. K., Bjø rnerheim, R., Brekke, M., Müller, C., Hopp, E., Ragnarsson, A., Brinchmann, J. E. and Forfang, K. r. Intracoronary injection of mononuclear bone marrow cells in acute myocardial infarction. N. Engl. J. Med. 355, 1199-1209 (2006).

[28] Marban, E. and Malliaras, K. Mixed results for bone marrow-derived cell therapy for ischemic heart disease Jama 308, 2405-2406 (2012).

[29] McCall, F. C., Telukuntla, K. S., Karantalis, V., Suncion, V. Y., Heldman, A. W., Mushtaq, M., Williams, A. R. and Hare, J. M. Myocardial infarction and intramyocardial injection models in swine Nat. Protoc. 7, 1479-1496 (2012).

[30] Nikolic, S. D., Khairkhahan, A., Ryu, M., Champsaur, G., Breznock, E. and Dae, M. Percutaneous Implantation of an Intraventricular Device for the Treatment of Heart Failure: Experimental Results and Proof of Concept J. Card. Fail. 15, 790-797 (2009).

[31] Qian, L., Huang, Y., Spencer, C. I., Foley, A., Vedantham, V., Liu, L., Conway, S. J., $\mathrm{Fu}$, J.-d. and Srivastava, D. In vivo reprogramming of murine cardiac fibroblasts into induced cardiomyocytes. Nature 485, 593-8 (2012).

[32] Rausch, M. K., Dam, A., Göktepe, S., Abilez, O. J. and Kuhl, E. Computational modeling of growth: Systemic and pulmonary hypertension in the heart Biomech. Model. Mechanobiol. 10, 799-811 (2011). 
[33] Rice, J. J., Wang, F., Bers, D. M. and de Tombe, P. P. Approximate model of cooperative activation and crossbridge cycling in cardiac muscle using ordinary differential equations. Biophys. J. 95, 2368-90 (2008).

[34] Rodriguez, E., Hoger, A. and McCulloch, A. D. Stress-dependent finite growth in soft elastic tissues J. Biomech. 27, 455-467 (1994).

[35] Rosenzweig, A. Cardiac cell therapy-mixed results from mixed cells. N. Engl. J. Med. 355, 1274-1277 (2006).

[36] Shimkunas, R., Makwana, O., Spaulding, K., Bazargan, M., Khazalpour, M., Takaba, K., Soleimani, M., Myagmar, B.-E., Lovett, D. H., Simpson, P. C., Ratcliffe, M. B. and Baker, A. J. Myofilament dysfunction contributes to impaired myocardial contraction in the infarct border zone AJP Hear. Circ. Physiol. 307, H1150-H1158 (2014).

[37] Streeter, D. D., Spotnitz, H. M., Patel, D. P., Ross, J. and Sonnenblick, E. H. Fiber orientation in the canine left ventricle during diastole and systole. Circ. Res. 24, 339-47 (1969).

[38] Sundnes, J., Wall, S., Osnes, H., Thorvaldsen, T. and McCulloch, A. D. Improved discretisation and linearisation of active tension in strongly coupled cardiac electromechanics simulations. Comput. Methods Biomech. Biomed. Engin. 17, 604-15 (2014).

[39] Sutton, M. and Sharpe, N. Clinical Cardiology : New Frontiers Left Ventricular Remodeling After Myocardial Infarction Pathophysiology and Therapy Circulation 101, 29812988 (2000).

[40] Szabo, T., Doehner, W. and Anker, S. D. Systolic heart failure. N. Engl. J. Med. 362, 1545 (2010).

[41] Velagaleti, R. S., Pencina, M. J., Murabito, J. M., Wang, T. J., Parikh, N. I., D'Agostino, R. B., Levy, D., Kannel, W. B. and Vasan, R. S. Long-term trends in the incidence of heart failure after myocardial infarction Circulation 118, 2057-2062 (2008).

[42] Wall, S. T., Walker, J. C., Healy, K. E., Ratcliffe, M. B. and Guccione, J. M. Theoretical impact of the injection of material into the myocardium: A finite element model simulation Circulation 114, 2627-2635 (2006).

[43] Weisman, H. F. and Healy, B. Myocardial infarct expansion, infarct extension, and reinfarction: pathophysiologic concepts. Prog. Cardiovasc. Dis. 30, 73-110 (1987).

[44] Wenk, J. F., Wall, S. T., Peterson, R. C., Helgerson, S. L., Sabbah, H. N., Burger, M., Stander, N., Ratcliffe, M. B. and Guccione, J. M. A method for automatically optimizing medical devices for treating heart failure: designing polymeric injection patterns. $J$. Biomech. Eng. 131, 121011 (2009). 
[45] Williams, A. R., Trachtenberg, B., Velazquez, D. L., McNiece, I., Altman, P., Rouy, D., Mendizabal, A. M., Pattany, P. M., Lopera, G. A., Fishman, J., Zambrano, J. P., Heldman, A. W. and Hare, J. M. Intramyocardial stem cell injection in patients with ischemic cardiomyopathy: functional recovery and reverse remodeling. Circ. Res. 108, 792-6 $(2011 a)$.

[46] Williams, A. R., Trachtenberg, B., Velazquez, D. L., McNiece, I., Altman, P., Rouy, D., Mendizabal, A. M., Pattany, P. M., Lopera, G. A., Fishman, J., Zambrano, J. P., Heldman, A. W. and Hare, J. M. Intramyocardial stem cell injection in patients with ischemic cardiomyopathy: functional recovery and reverse remodeling. Circ. Res. 108, 792-6 $(2011 b)$.

[47] Winslow, R. L., Rice, J., Jafri, S., Marban, E. and O'Rourke, B. Mechanisms of Altered Excitation-Contraction Coupling in Canine Tachycardia-Induced Heart Failure, II : Model Studies Circ. Res. 84, 571-586 (1999).

[48] Xin, M., Olson, E. N. and Bassel-Duby, R. Mending broken hearts: cardiac development as a basis for adult heart regeneration and repair. Nat. Rev. Mol. Cell Biol. 14, 529-41 (2013).

[49] Yu, C.-M., Bleeker, G. B., Fung, J. W.-H., Schalij, M. J., Zhang, Q., van der Wall, E. E., Chan, Y.-S., Kong, S.-L. and Bax, J. J. Left ventricular reverse remodeling but not clinical improvement predicts long-term survival after cardiac resynchronization therapy. Circulation 112, 1580-1586 (2005). 